Portland State University

PDXScholar

10-1972

\title{
Social Desirability and the Interpersonal Check List
}

Deborah Jean Wheeler

Portland State University

Follow this and additional works at: https://pdxscholar.library.pdx.edu/open_access_etds

Part of the Psychology Commons

Let us know how access to this document benefits you.

\section{Recommended Citation}

Wheeler, Deborah Jean, "Social Desirability and the Interpersonal Check List" (1972). Dissertations and Theses. Paper 1570.

https://doi.org/10.15760/etd.1570

This Thesis is brought to you for free and open access. It has been accepted for inclusion in Dissertations and Theses by an authorized administrator of PDXScholar. Please contact us if we can make this document more accessible: pdxscholar@pdx.edu. 
AN ABSTRACT OF THE THESIS OF Deborah Jean Wheeler for the Master of Science in Psychology presented October 19,1972.

Title: Social Desirability and the Interpersonal Check List.

APPROVED BY MEMBERS OF THE THESIS COMMITTEE:

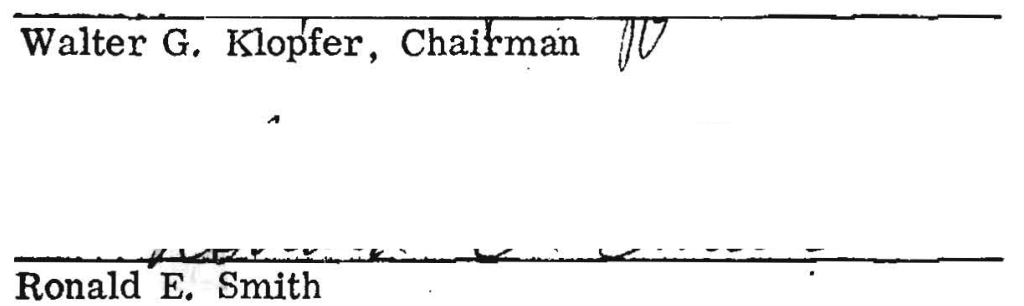

Ronald E. Smith

$\overline{\text { Max Reed }}$

The purpose of this study is to investigate whether number of responses

is related to the social desirability and intensity of the test items. 61 Ss were administered the Interpersonal Check List and the Marlowe Crowrie Social Desirability Scale. From the Interpersonal Check List number of responses, average item intensity and average item social desirability were calculated. Average item social desirability was calculated from individual item social desirability values obtained from ratings by another, similar $S$ group. The results showed that number of responses is negatively correlated with average 
Item social desirability and positively correlated with average item intensity, as predicted. Social desirability and intensity are negatively correlated. Data pertaining to the Marlowe Crowne scale, a measure of the tendency of an individual $\underline{\mathrm{S}}$ to respond in a socially desirable manner, were inconclusive. It is concluded that a $\underline{S}$ giving a low number of responses on the Interpersonal Check List is probably trying to create a good impression by refusing to endorse extreme or undesirable test items. 
SOCIAL DESIRABILITY AND THE

INTERPERSONAL CHECK LIST

by

DEBORAH JEAN WHEELER

A thesis submitted in partial fulfillment of the requirements for the degree of

\section{MASTER OF SCIENCE \\ in PSYCHOLOGY}

Portland State University 1972 
TO THE OFFICE OF GRADUATE STUDIES AND RESEARCH:

The members of the Committee approve the thesis of Deborah Jean

Wheeler presented October 19, 1972.

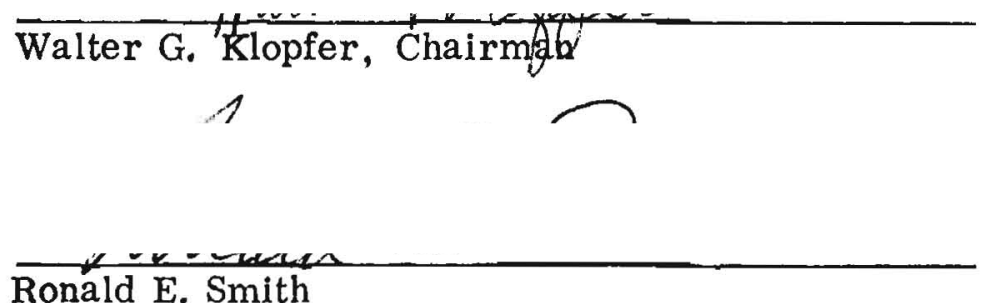

Ronald E. Smith

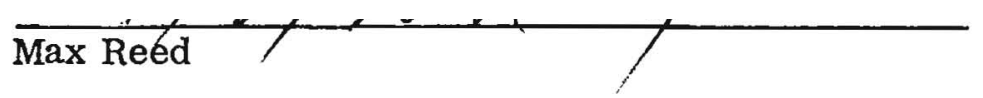

\section{APPROVED:}

Ronald E. Smith, Head, Department of Psychology

7

David T. Clark, Dean of Graduate Studies and Research

October 19, 1972 


\section{ACKNOWLEDGMENTS}

Special thanks go to the members of my thesis committee, Dr. Walter G. Klopfer, chairman, Dr. Ronald Smith, and Dr. Max Reed, for their patience and encouragement. I also wish to thank Dale Walhood, Andrew Homer and Dr. Rolf LaForge for their kind assistance, Calligrapher Laureate Lloyd J. Reynolds for his clear vision, and my husband, Richard, for himself. 
TABLE OF CONTENTS

PAGE

ACKNOWLEDGMENTS. ................ i iii

LIST OF TABLES. ..................... . . . . .

LIST OF FIGURES. . . . . . . . . . . . . . vii

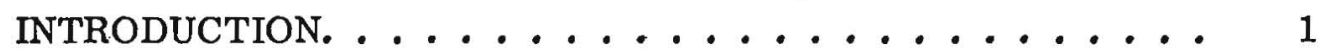

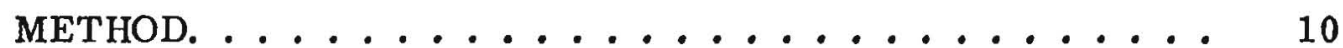

RESULTS. . . . . . . . . . . . . . . 12

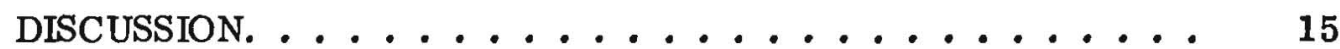

CONCLUSIONS. . . . . . . . . . . . . . . . 21

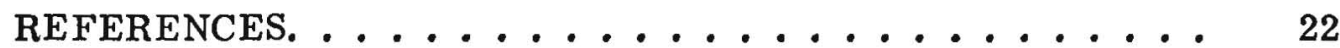

APPENDIX

A Interpersonal Check List Items With Intensity and Social Desirability Values for Each Item. . . . . 24

B The Marlowe Crowne Social Desirability Scale. . . 29 


\section{LIST OF TABLES}

TABLE

PAGE

I Means and Standard Deviations of NIC, AIN, ICL-SD and Marlowe Crowne Scores............ 13

II Correlation Coefficients for NIC, AIN, ICL-SD, and Marlowe Crowne scores.................. 14 


\section{LIST OF FIGURES}

FTGURE

PAGE

1 Personality variables on the Interpersonal

Check List with bilateral axes shown...... 


\section{INTRODUCTION}

What does it mean when a person doesn't say much about himself? Does he not say much about anything, or is he refusing to say something in particular about himself? In ordinary conversation, communication includes many sorts of nonverbal messages such as facial expressions, gestures, tone of voice, and length of pauses in the conversation. In paper and pencil tests, however, only certain kinds of verbal communications are admitted. $\underline{\mathrm{S}}$ is asked to respond only in a particular way, such as by checking off true or false items, and his responses are structured by the test situation.

In some kinds of tests, $\underline{S}$ is given the option of not responding to any given

item. An example of this sort is the Interpersonal Check List (Freedman, Leary, Ossorio, \& Coffey, 1951; LaForge, Leary, Naboisek, \& Coffey, 1954; Leary \& Coffey, 1955; LaForge \& Suczels, 1955), which will be described more fully below. In this test, $\underline{\mathrm{S}}$ may check off as few or as many answers as he wishes. The items in the test are adjectives which can be used to describe the $\underline{S}$ taking the test; the test is often used for self-description. If $\underline{S}$ gives only a few answers, he might be eliminating certain kinds of responses or he might be restricting the number but not the type of his answers. Some Ss may use more words to describe themselves, or anything else, than do other Ss. They would also give many worded answers to such tests as the Thematic Apperception Test and the Sentence

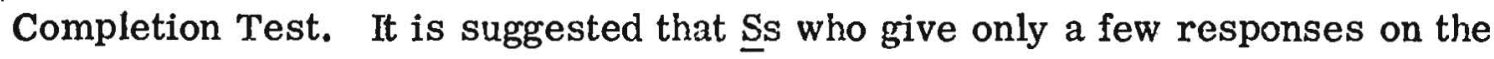


Interpersonal Check List (ICL) are following one of two patterns: using only a few terms to describe themselves; or choosing only certain kinds of answers. These two patterns might be distinguished by some quality of the answers which varies with their number. Such a quality might be the social desirability of the test items.

Test items considered to be high in social desirability are those which tend to create a good impression of the $\underline{S}$ endorsing them (Edwards, 1957a; Crowne \& Marlowe, 1964). There seem to be some kinds of attributes which most people will acknowledge, others which few people will acknowledge, and still more which vary from person to person. It is suggested that for an item to be included in the first category, those which most people will answer, it must be widespread in occurrance and socially desirable. Rosen (1956) discusses the question of whether traits are socially desirable because they are widespread and the average defines the ideal (most people are $\mathrm{x}$, therefore it is good to be $\mathrm{x}$ ), or widespread because they are socially desirable and most people want to present themselves in a favorable light (it is good to be $x$, so most people say that they are $\mathrm{x}$ ). However, not all widespread traits may be socially desirable, but it seems likely that such traits will not be endorsed by most people.

Social desirability can be measured by either measuring the social desirability of an individual test item, or measuring the tendency of an individual $\underline{\mathrm{S}}$ to respond in a socially desirable manner, that is, to create a good impression. Edwards $(1957 \mathrm{a}, \mathrm{b})$ developed a technique to evaluate the social desirability of test items. He had judges rate the items on a seven point scale ranging from Very Undesirable through Neutral to Very Desirable. These ratings were then averaged to give a 
unique score for each item. Edwards and others (Edwards, 1953, 1957a, b; Taylor, 1961) found that these scores were strongly correlated $(\underline{r}=.87)$ with the probabilities that the items will be endorsed. That is, the more socially desirable an item is considered, the more people will endorse it and, conversely, the less desirable it is, the fewer people will acknowledge it. This relationship does not change much under conditions of anonymity, which means that even when they will not be identified with their answers, people endorse socially

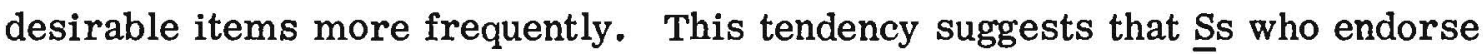
socially desirable items are not consciously lying to create a good impression, but believe that they do possess these qualities and are behaving in a manner consistent with their self image.

The ratings of social desirability obtained by Edwards do not seem to vary very much from one individual to another when they are within the same culture. Edwards had used undergraduate college students in his original studies but later workers tested

Nisei, ... hospitalized psychiatric patients and 'Skid Row' alcoholic tuberculosis patients, ... high school students from different socioeconomic classes, ... and Norwegians

to find

ratings dramatically similar to those of the ... original study. ... There appears to be widespread agreement on what is socially desirable among groups presumably varying greatly in cultural background, social position, and personality.

(Crowne \& Marlowe, 1964, p. 13) 
So, ratings made by one group of $\underline{S} s$ are probably valid for another, similar group, especially if they are samples drawn from the same population, such as all university students.

In order to measure the tendency of an individual $\underline{\mathrm{S}}$ to respond in a socially desirable manner, Edwards (1957a) compiled a test using items from the $\underline{F}, \underline{K}$, and $\underline{\mathrm{L}}$ scales of the MMPI, and from the Taylor Manifest Anxiety Scale. A high score on the Edwards Social Desirability Scale is supposed to indicate a tendency to endorse only socially desirable items, that is, to choose answers that will produce a good impression. However, this scale has been criticized (Crowne \& Marlowe, 1960; Scott, 1963) because the tests its items were drawn from were designed to detect abnormal rather than undesirable behaviors. Crowne and Marlowe (1960) found that the Edwards scale correlates strongly with MMPI clinical scales, for instance, $\underline{\mathbf{r}}=-.80$ with $\underline{\mathrm{Pt}},-77$ with $\underline{\mathrm{Sc}}$, and -.73 with $\underline{\mathrm{Pd}}$. Thus, scores on the Edwards scale may reflect presence or absence of pathology rather than the tendency of a person to present himself in a favorable light. For example, when a $\underline{\mathbf{S}}$ denies having symptoms such as hallucinations, he may actually not have them, and his denial is not primarily based upon the undesirable nature of bizarre behavior.

The Edwards scale is also not normally distributed, but negatively skewed with scores piling up at the high end. A single high score loses meaning when

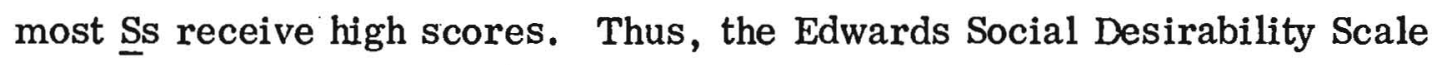
leaves much to be desired as a measure of social desirability.

A more recently developed test, the Marlowe Crowne Social Desirability 
Scale, was constructed to eliminate the problems of the reflection of pathology rather than social desirability, and skewed distribution of scores. Items were selected which were culturally desirable but improbable:

To be included, an item had to meet the criterion of cultural approval and yet be untrue of virtually all people, and have minimal pathological or abnormal implications.

(Crowne \& Marlowe, 1964, p. 22)

Most of the items on the Marlowe Crowne scale are statements of behaviors which are generally approved or condemned, but which do not reflect the actual occurrence of these acts. In other words, these test items are things which people preach but rarely practice. While an occasional item might be in truth the way a person behaves, the test is normed to consider this possibility. The text of the Marlowe Crowne Social Desirability Scale is presented in Appendix B.

Marlowe Crowne scores do not correlate significantly with most MMPI clinical scales (Crowne \& Marlowe, 1964), indicating that the test probably does not reflect frequency of maladjustive symptoms. Also, the scores are normally distributed, in contrast to the skewed distribution of the scores of the Edwards Social Desirability Scale. Other workers have used the Marlowe Crowne scale as a measure of social desirability set. Pervin and Lilly (1967) interpreted high Marlowe Crowne scores as a need to obtain approval by responding in a culturally appropriate and acceptable manner; they found Marlowe Crowne scores to be related to "high self concept" (on the semantic differential) and to low self-ideal self discrepancies (for evaluative scales). 
That is, people who score high on the Marlowe Crowne perceive themselves as being close to their ideal selves, which are pretty favorable. Strickland and Crowne (1962) found that Ss who scored high on the Marlowe Crowne scale tended to conform (obtain the approval of others by acting in a socially desirable manner) in Asch-type settings (Asch, 1956).

On the basis of these studies, the Marlowe Crowne Social Desirability Scale seems to be a meaningful measure of social desirability. It would be reasonable to expect Marlowe Crowne scores to correlate with other measures of social desirability, for instance, those of individual test items.

It is the purpose of this study to compare social desirability ratings, of both test items (following the techniques of Edwards, $1957 \mathrm{a}, \mathrm{b}$ ) and of individual Ss (using the Marlowe Crowne Social Desirability Scale) with number of responses on the Interpersonal Check List.

The Interpersonal Check List (Freedman, Leary, Ossorio, \& Coffey, 1951; LaForge, Leary, Naboisek, \& Coffey, 1954; Leary \& Coffey, 1955; LaForge \& Suczek, 1955; LaForge, 1963) is an objective personality test which consists of a list of adjectives describing how a person might interact with others. The Check List can be used to describe oneself, ideal self, or another, such as a friend or parent; $\underline{S}$ checks off those items which he feels pertain to the figure described. This study will consider only the instance of self description on the Interpersonal Check List (ICL). The resulting protocol is a profile of the figure along personality variables such as dependence or dominance, and can be scored in a variety of ways, including summary scores and a graph. The entire 
protocol can be visually displayed on a circular graph, with approximately vertical and horizontal axes representing the bilateral dimensions of Love-Hate and Dominance-Submission. Octants and sixteenths are frequently used divisions of this graph. The circular graph with personality variables is shown in Figure 1. Items on the Check List are shown in Appendix A.

On the Interpersonal Check List (ICL), the total number of responses, regardless of what personality dimension they occur in, is called NIC (Number of Items Checked). The authors of the ICL (LaForge, 1963) suggest that this score may reflect acquiescence as a response set, this is, the tendency of a $\underline{S}$ to agree with test items regardless of their content. There is, however, no evidence that Ss who check off a large number of answers are "yes-people", agreeing to everything in sight. Nor does there seem to be any way of distinguishing between them and Ss who use a large number of chosen items to describe themselves.

Another score on the ICL, called AIN (Average Intensity of Response), is supposed to represent both the intensity and social desirability of the responses. AIN is the average of the intensity values of all items checked off by a single $\underline{S}$. The intensity values were originally obtained from ratings by five psychologist judges. These values range in increasing magnitude from 1 to 4 , and all are whole numbers. First, judges rated items which were being considered for the ICL, as mentioned above. Then tests composed of these items were given to a group of Ss (clinic outpatients) and the values were reworked so that a particular percentage of Ss taking the test would check off items of a given intensity. For instance, $9 / 10$ of the Ss checked off items of intensity 1 . Intensity 1 , the least 


\section{Figure 1}

Personality Variables on the ICL with bilateral axes shown
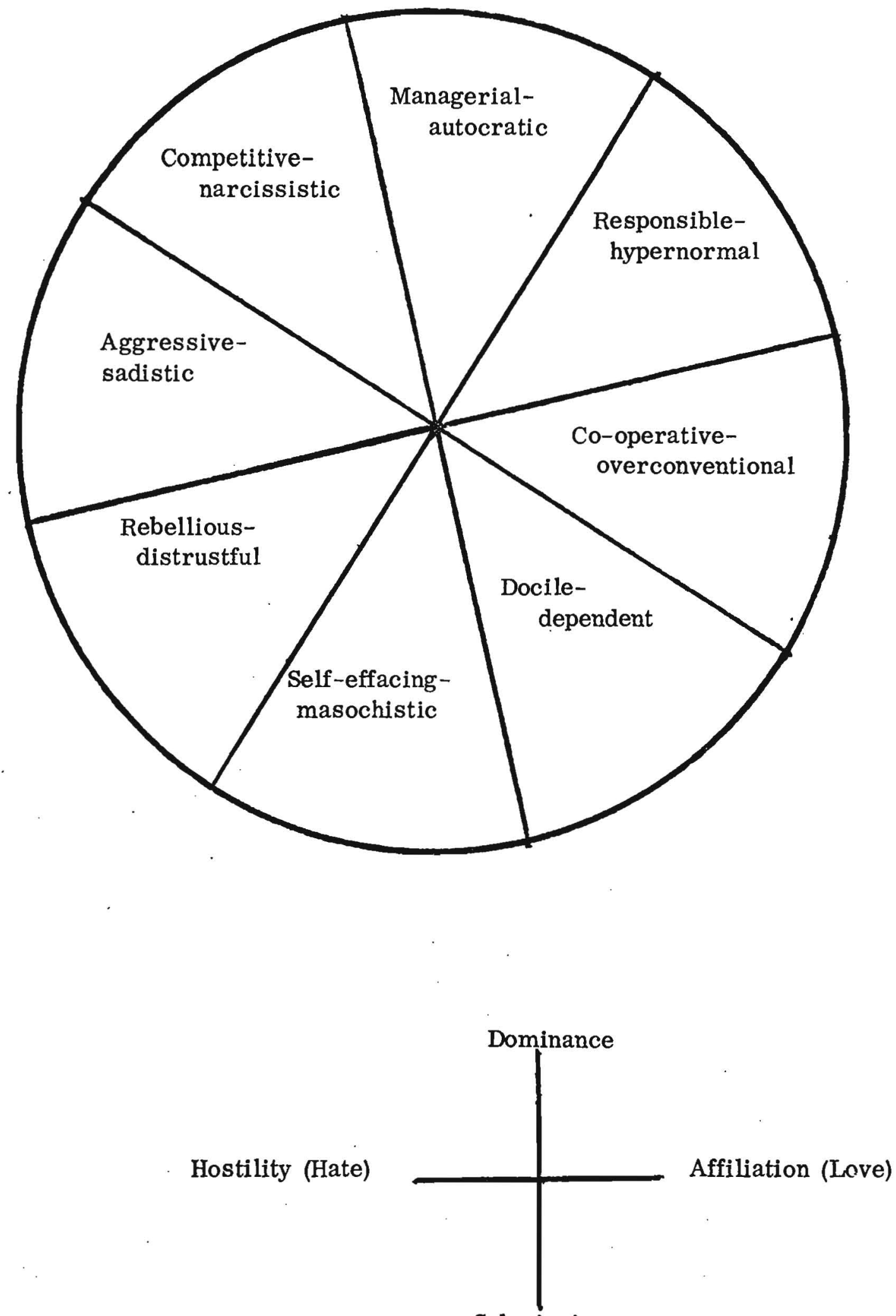

Submission 
intense value, is endorsed by most people. On the basis of Edwards's work, it would seem likely that adjectives of low intensity values would have high social desirability because the probability of their being endorsed (.90 for intensity 1$)$ is high. As the intensity increases, the portion of people checking off those items decreases. $2 / 3$ of the $\underline{S}$ in the original study checked off items of intensity $2,1 / 3$ of intensity 3 , and $1 / 10$ of intensity 4 . These fractions add up to more

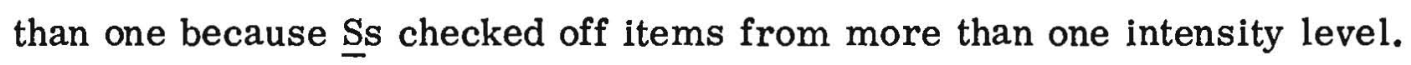

On the basis of the relationships between intensity value, probability of endorsement, and social desirability, it seems reasonable to expect social desirability to be correlated with intensity on the ICL. Kogan (in LaForge, 1963) compared intensity and social desirability ratings by neuropsychiatric patients $(\underline{N}=46)$ and by university students $(\underline{N}=94)$ to find correlations of -.74 and -.73 , respectively. Thus, intensity and social desirability seem to be closely related on the ICL.

Intensity is also held constant between personality variables on the ICL. That is, there is not one variable that has all less intense items and another which has all more intense items. The authors wanted all of the personality variables to have an equal statistical chance of being endorsed. They chose items so that within each sixteenth there is one item of intensity 1 , three of 2 , three of 3 , and one of 4 . The test is not completely balanced along the Love-Hate dimension, however, since it is difficult to find mild or desirable expressions of hate or extreme, undesirable expressions of love. 


\section{METHOD}

The specific problem under consideration is whether number of responses on the ICL is related to social desirability and intensity. In this study, AIN will be used as the measure of intensity level, and social desirability will be measured by the Marlowe Crowne Social Desirability Scale and by a new measure, the ICL-SD.

\section{ICL-SD}

The ICL-SD is the average of the social desirability values of the items checked off on a particular protocol. These social desirability values were determined following the method of Edwards (1957a). Twenty-two Portland State University and Reed College students, distinct from the experimental group, rated all ICL items on a five point scale of social desirability, where -2.00 equals Very Undesirable, 0.00 equals Neutral, and 2.00 equals Very Desirable. Ratings were pooled across sex and school, and a unique averaged value was calculated for each item. A table of ICL-SD values is presented in Appendix A.

\section{HYPOTHESES}

It is expected that number of responses will be correlated with item intensity and with social desirability as measured both by the ICL-SD and by the Marlowe Crowne Social Desirability Scale. Therefore, the following specific hypotheses 
are made:

1. Number of responses (NIC) is correlated with social desirability. NIC is negatively correlated with ICL-SD and positively correlated with AIN. NIC is negatively correlated with Marlowe Crowne scores.

2. Social desirability is correlated with intensity. ICL-SD is negatively correlated with AIN.

3. The two measures of social desirability are correlated. ICL-SD is positively correlated with the Marlowe Crowne scale.

\section{PROCEDURE}

Sixty-one Portland State University undergraduate summer school students

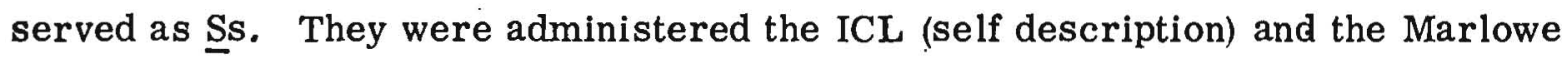
Crowne Social Desirability Scale, which were stapled together to insure proper

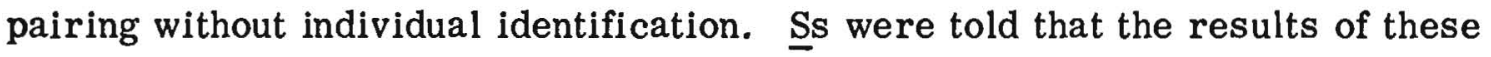
tests were to be anonymous and were asked not to write their names on the forms. ICL-SD scores were determined for each protocol using the ratings previously obtained. The Marlowe Crowne score, NIC, and AIN were also determined. Correlations between these measures were calculated using the Pearson productmoment technique. 


\section{RESULTS}

Means and standard deviations for the data are presented in Table I.

Correlation coefficients between NIC, AIN, ICL-SD, and the Marlowe Crowne scores are presented in Table II. NIC is shown to be correlated with AIN and ICL-SD, as predicted, but not with the Marlowe Crowne. The ICL-SD is correlated with AIN. However, the final hypothesis, that ICL-SD is correlated with the Marlowe Crowne scale, is not upheld by the data.

The data support all hypotheses except those pertaining to the Marlowe Crowne Social Desirability Scale. 
TABLE I

MEANS AND STANDARD DEVIATIONS OF NIC, AIN, ICL-SD AND MARIOWE CROWNE SCORES

$\begin{array}{lcc}\text { Measure } & \text { Mean } & \text { Standard Deviation } \\ \text { NIC } & 39.83 & 12.68 \\ \text { AIN } & 1.89 & 0.24 \\ \text { ICL-SD } & 0.52 & 0.10 \\ \text { Marlowe Crowne } & 12.66 & 4.89 \\ & & \\ \underline{N}=61 & & \\ \end{array}$


TABLE II

CORRELATION COEFFICIENTS FOR NIC, AIN, ICL-SD, AND MARLOWE CROWNE SCORES

$\begin{array}{lccc} & \text { AIN } & \text { ICL-SD } & \text { Marlowe Crowne } \\ \text { NIC } & .54 * * & -.31 * * & .13 \mathrm{n.s.} \\ \text { AIN } & & -.75 * * & .31 * * \\ \text { ICL-SD } & & & .20 \mathrm{n.s.}\end{array}$

$\underline{N}=61$

** $\mathrm{p}<.01$ 


\section{DISCUSSION}

The data have upheld the basic assumption that number of responses varies with item social desirability and intensity. Specifically, number of responses is inversely related to social desirability, meaning the fewer the number of responses, the more socially desirable the responses tend to be. Number of responses is directly related to item intensity, meaning the greater the number, the more extreme the responses tend to be.

Intensity and social desirability are themselves highly correlated, a result which is not surprising since they are both related to number of responses. This relationship was also initially expected because social desirability and probability of endorsement are strongly related (Edwards, 1953) and intensity levels were set up with specified probabilities of endorsement. For example, most Ss $(9 / 10)$ will endorse items from itensity level 1 , and items which have a high probability of endorsement are socially desirable. This argument presumes that intensity and social desirability are actually different things, and that AIN (the measure of intensity) does measure item intensity. If social desirability and intensity are indeed separable, there should, theoretically, exist at least some intense, desirable and nonintense, undesirable traits. However, none of these items appear in the ICL. The ICL contains only those items for which social desirability and intensity are inversely related. Of the 
16 items of intensity 4, only one ("loves everybody") was judged socially desirable in this study and its rating was +.411 , or between Slightly Desirable and Neutral. Ten of the 16 items of intensity 4 were rated between Slightly Undesirable and Very Undesirable. Every item of intensity 1 was rated as socially desirable, 13 of the 16 between Slightly Desirable and Very Desirable. The authors of the ICL claim that they have included social desirability effects in the ICL by controlling the frequency distribution of intensity values (LaForge, 1963). It seems that, in actuality, intensity and social desirability in AIN have been made inseparable by the elimination from the ICL of extreme, desirable, and nonextreme, undesirable items, as indicated by the above ratings.

Another possibility is that social desirability and intensity are indeed inseparable, one being a component of the other. It seems likely that item intensity and social desirability in our society might be inherently related, that is, part of the definition of social desirability is lack of intensity. If this is the case, then the judges who originally assigned intensity values to the items of the ICL may well have been responding to a set of variables which included both social desirability and intensity. In this case, AIN appears to be a round-about way of measuring social desirability. It has the advantage of being relatively balanced in terms of frequency distribution and balance within each personality variable, but ICL-SD has the advantage of being more accurate. Each item has a score, not necessarily unique, which has not been rounded off (to a whole number) and is therefore more precise. There is no way of estimating the cumulative error of using rounded off intensity values over a protocol of, for instance, 40 
items. However, it is to be hoped that such errors would be consistent from protocol to protocol.

The Marlowe Crowne Social Desirability Scale data are puzzling. Scores on the Marlowe Crowne are not correlated with ICL-SD, as expected, but they are correlated with AIN in the reverse of the predicted direction. If the Marlowe Crowne does measure social desirability, then it should correlate positively with ICL-SD and negatively with AIN, and it does neither. The results of the

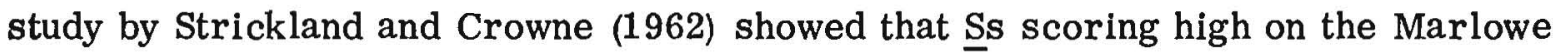
Crowne tended to conform in Asch-type settings. In Asch's study (1956), $\underline{\mathrm{S}}$ was presented with a choice of being alone in making an accurate judgment or of

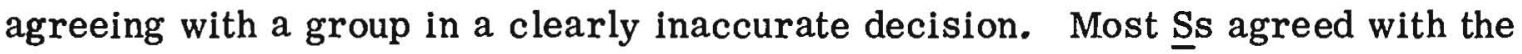
group. If being objectively accurate or right and being "true to oneself" are socially desirable, then these $\underline{S}$ were behaving in a conformist but undesirable fashion. The ICL item "agrees with everyone" was rated in this study as -1.636 , or as between Slightly Undesirable and Very Undesirable, while the item "independent" was valued at +1.591 , or between Slightly Desirable and Very Desirable. So, expressions of excessive conformity seem to be generally considered as socially undesirable. It seems likely that social desirability and conformity are not the same thing, and the Marlowe Crowne scale may be measuring conformity or some variable other than social desirability.

Another explanation for the lack of correlation between the Marlowe Crowne and the ICL-SD lies in the peculiar characteristics of the $\underline{S}$ sample, university 
students. A pilot study conducted with a mixed student-nonstudent sample did show a correlation in the expected direction $(\underline{r}=.56 ; \underline{p}<.05 ; \underline{N}=13)$ between the Marlowe Crowne and the ICL-SD. Students are probably unusually adept at "second-guessing" test questions of the true-false type, which comprise the Marlowe Crowne. Ss may well be answering these test items not on the basis of what they believe constitutes a good impression, but rather on the basis of what they think $\underline{\mathrm{E}}$ believes to be a good impression. In a test-sophisticated population this difference may be significant, especially since many of the Marlowe Crowne items are rather transparent:

If I could get into a movie without paying and be sure I was not seen, I would probably do it. (Scored False)

I don't find it particularly difficult to get along with loud mouthed, obnoxious people. (Scored True)

In addition, norms for the Marlowe Crowne were calculated over a decade ago, and it is possible that the pattern of socially desirable behavior for university students has changed, especially in the light of contemporary challenges to authority, such as demonstrations, occupations and other confrontations. In other words, it may have become more socially desirable, in the student subculture at any rate, to be nonconformist and rebellious. In 1960 Marlowe and Crowne found a mean of 13.72 (standard deviation, 5.78 ) for the social desirability scale. The present study yielded a mean of 12.66 (standard deviation, 4. 89). These differences are not significant (one-tailed t-test, $a=.05$ ), but this may be due to the fact that the present sample is much smaller in size than the group 
Marlowe and Crowne used. If a larger sample yields a significant difference, the lowered score would indicate that today's students do consider themselves less conforming to the standards of socially required behavior than did their predecessors of more then ten years ago. Clearly, further research using $\underline{S}$ groups of differing test experience is called for. Also, it might be fruitful to compare responses to the Marlowe Crowne test items when administered as a true-false test (the original format) or as a sort of check list in which only those items considered true are endorsed.

Eliminating the inconclusive Marlowe Crowne results, the data reveal two patterns of response to the ICL: fluency, that is, the use of many worlds to describe oneself, paired with a willingness to make extreme and socially undesirable statements about oneself; and conservativeness in number, social desirability,

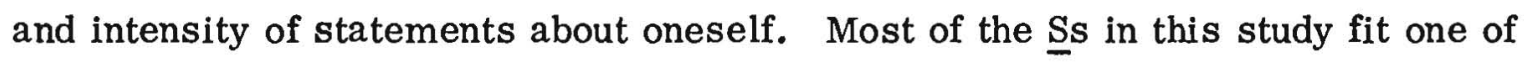
the two patterns, or were moderate in number, social desirability, and intensity of their statements. However, atypical pattersn, such as low number and low social desirability (high intensity) do exist, and in the interpretation of an individual protocol it would seem desirable to be able to identify these patterns. With NIC (number of responses) alone, the rest of the pattern can only be predicted, for instance, a low NIC is usually accompanied by a high ICL-SD and low AIN. This is the kind of $\underline{S}$ who is generally conservative, who is excluding certain kinds of responses, such as extreme or socially undesirable items, from his answers. On the other hand, if ICL-SD is found to be low and AIN to be high, then the $\underline{S}$ is probably a person who uses few words to describe 
himself, but is not eliminating particular types of responses. Therefore, it seems advantageous to have available NIC and either AIN or ICL-SD for the interpretation of an individual protocol. 


\section{CONCLUSIONS}

The purpose of this study was to investigate whether number of responses on the Interpersonal Check List was related to social desirability and to the intensity of the test items. Two measures of social desirability were used, individual item social desirability and the tendency of an individual $\underline{S}$ to respond in a socially desirable manner. The data showed that number of responses is correlated with item social desirability (negatively) and with item intensity (positively). The relationship between social desirability and intensity is unclear since the two variables do not seem to be separable on the ICL.

It is concluded that a low number of responses (NIC) on the ICL is generally related to low response intensity (AIN) and to high average item social desir-

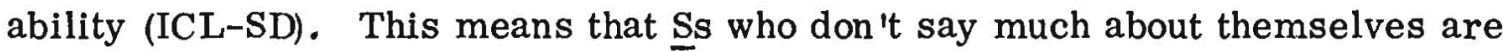
usually trying to create a good impression of themselves by refusing to admit to anything extreme or socially undesirable. Atypical patterns can be identified by inspection of NIC plus another measure, AIN or ICL-SD. Thus, Ss who use few words to describe themselves (or anything else) can be distinguished from Ss who are eliminating extreme or undesirable responses.

No conclusions can be drawn from the Marlowe Crowne Social Desirability Scale data, except that the Marlowe Crowne does not correlate with any other measure in the predicted manner. Further research is indicated to understand more precisely what the Marlowe Crowne measures. 


\section{REFERENCES}

Asch, S. Studies of independence and conformity: I. A minority of one against a unanimous majority. Psychological Monographs, 1956, 70, No, 9 (Whole No. 416).

Crowne, D. P. \& Marlowe, D. A new scale of social desirability independent of psychopathology. Journal of Consulting Psychology, 1960, 24, 349-354.

Crowne, D. P. \& Marlowe, D. The approval motive: Studies in evaluative dependence. New York: Wiley, 1964.

Edwards, A. L. The relationship between the judged desirability of a trait and the probability that the trait will be endorsed. Journal of Applied Psychology, $1953, \underline{37}, 90-93$.

Edwards, A. L. The social desirability factor in personality assessment and research. New York: Dryden Press, 1957 (a).

Edwards, A. L. Social desirability and probability of endorsement of items in the interpersonal check list. Journal of Abnormal \& Social Psychology, 1957, $\underline{55}, 394-396$ (b).

Edwards, A. L. Social desirability and the description of others. Journal of Abnormal \& Social Psychology, 1959, 59, 434-435.

Edwards, A. L. \& Diers, C. J. Neutral items as a measure of acquiescence. Educational and Psychological Measurement, 1963, 23, 687-698.

Freedman, M. B., Leary, T. F., Ossorio, A. G. \& Coffey, H. S. The interpersonal dimension of personality. Journal of Personality, 1951, 20, 143-151.

Husek, T. R. Acquiescence as a response set and as a personality characteristic. Educational and Psychological Measurement, 1961, 21, 295-307.

Kogan, W. S. \& Fordyce, W. E. The control of social desirability: A comparison of three different $Q$ sorts and a check list, all composed of the same items. Journal of Consulting Psychology, 1962, 26, 26-30. 
LaForge, R. Research Use of the ICL. Oregon Research Institute Technical Report (Volume 3, No. 4), 1963.

LaForge, R., Leary T. F., Naboisek, H., Coffey, H., \& Freedman, M. B. The interpersonal dimension of personality: $\Pi$. An objective study of repression. Journal of Personality, 1954, 23, 129-154.

LaForge, R. \& Suczek, R. F. The interpersonal dimension of personality: III. An interpersonal checklist. Journal of Personality, 1955, 24, 94-112.

Leary, T. F. The interpersonal diagnosis of personality. New York: Ronald Press, 1957.

Leary, T. F. \& Coffey, H. S. Interpersonal diagnosis: Some problems of methodology and validation. Journal of Abnormal \& Social Psychology, $1955,50,110-124$.

Pervin, L. A. \& Lilly, R. S. Social desirability and self and ideal self ratings on the semantic differential. Educational and Psychological Measurement, $1967, \underline{27}, 845-853$.

Rosen, E. Self-appraisal, personal description, and perceived social desirability of personality traits. Journal of Abnormal \& Social Psychology, 1956, 52, 151-158.

Scott, W. A. Social desirability and individual conceptions of the desirable. Journal of Abnormal \& Social Psychology, 1963, 67, 574-585.

Strickland, B. \& Crowne, D. P. Conformity under conditions of simulated pressure as a function of the need for social approval. Journal of Social Psychology, 1962, 요, 171-181.

Taylor, J. B. What do attitude scales measure: The problem of social desirability. Journal of Abnormal \& Social Psychology, 1961, 62, 386-390. 


\section{APPENDIX A \\ INTERPERSONA L CHECK LIST ITEMS WITH INTENSTTY \\ AND SOCIAL DESIRABIITY VALUES FOR EACH \\ ITEM}

Item

Able to give orders

Appreciative

Apologetic

Able to take care of self

Accepts advice readily

Able to doubt others

Affectionate \& understanding

Acts important

Able to criticize self

Admires \& imitates others

Agrees with everyone

Always ashamed of self

Very anxious to be approved of

Always giving advice

Bitter

Bighearted \& unselfish

Boastful

Businesslike

Bossy

Can be frank \& honest

Clinging vine

Can be strict if necessary

Considerate

Cold \& unfeeling

Can complain if necessary
Intensity

1

1

2

1

2

1

2

3

1

2

4

4

2

3

3

2

3

3

2

1

4

1

1

4

1
Social Desirability

.857

1. 714

$-.454$

1.400

.863

.628

.682

$-.682$

1. $428^{\circ}$

$-.389$

$-1.636$

$-1.818$

$-.342$

$-1.259$

$-1.455$

1. 000

$-1.409$

.182

$-1.500$

1. 885

-1. 727

1. 056

1. 742

$-1.727$

1. 102 
Co-operative

Complaining

Can be indifferent to others

Critical of others

Can be obedient

Cruel \& unkind

Dependent

Dictatorial

Distrusts everybody

Dominating

Easily embarrassed

Eager to get along with others

Easily fooled

Egotistical \& conceited

Easily led

Encouraging others

Enjoys taking care of others

Expects everyone to admire him

Frequently disappointed

Firm but just

Fond of everyone

Forceful

Friendly

Forgives anything

Frequently angry

Friendly all the time

Generous to a fault

Gives freely of self

Good leader

Grateful

Hardboiled if necessary

Helpful

Hard-hearted

Hard to impress

Impatient with others' mistakes
1

3

2

2

1

4

3

4

4

2

2

2

3

4

2

2

2

4

2

2

3

2

1

3

3

3

3

2

2

1

2

1

4

2

3
1. 652

$-1.363$

$-.091$

$-.455$

.857

$-1.909$

$-.818$

$-1.682$

$-1.409$

$-1.455$

.500

.273

$-.682$

$-1.364$

$-1.000$

1. 227

.727

$-.773$

$-.542$

1. 273

.227

.636

1. 657

$-.300$

$-.909$

.455

.045

1. 227

1. 227

1. 323

1. 000

1. 470

$-1.227$

.273

$-1.227$ 
Independent

1.591

Irritable

$-1.227$

Jealous

$-1.409$

Kind \& reassuring

1. 318

Iikes responsibility

1.286

Lacks self-confidence

$-1.227$

Likes to compete with others

.363

Lets others make decisions

Likes everybody

$-.500$

Iikes to be taken care of

$-.455$

$-.636$

Loves everybody

Makes a good impression

Manages others

Meek

Modest

.411

.571

$-.381$

$-.762$

.529

Hardly ever talks back

Often admired

$-.441$

.682

Obeys too willingly

$-1.000$

Often gloomy

Outspoken

$-.850$

.809

Overprotective of others

Often unfriendly

Oversympathetic

Often helped by others

Passive \& unaggressive

$-1.045$

$-.955$

$-.909$

$-.091$

$-.909$

Proud \& self-satisfied

$-.136$

Always pleasant \& agreeable

1.176

Resentful

$-1.090$

Respected by others

1.045

Rebels against everything

$-1.136$

Resents being bossed

Self-reliant \& assertive

.591

1. 500

Sarcastic

$-.773$

Self-punishing

$-1.091$

Self-confident

1. 545 
Self-seeking .130

Shrewd \& calculating

$-.455$

Self-respecting

1. 575

Shy

$-.363$

Selfish

$-1.045$

Skeptical

Sociable \& neighborly

.682

Slow to forgive a wrong

.955

Somewhat snobbish

Spineless

$-1.091$

$-.818$

$-1.636$

Stern but fair

Spoils people with kindness

Straightforward \& direct

Stubborn

Too easily influenced by friends

864

$-.500$

1. 636

$-.182$

$-.955$

Thinks only of self

Tender \& softhearted

$-1.545$

Timid

Too lenient with others

Touchy \& easily hurt

.591

$-.864$

$-.636$

$-1.045$

Too willing to give to others

Tries to be too successful

Trusting \& eager to please

Tries to comfort everyone

Usually gives in

$-.364$

$-.634$

.318

$-.095$

$-.476$

Very respectful to authority

Wants everyone's love

$-.714$

$-.905$

1.093

Well thought of

$-1.143$

Wants to be led

$-1.273$

Will confide in anyone

Warm

1. 364

Wants everyone to like him

Will believe anyone

$-.591$

$-1.409$ 
Inte nsity: $1=$ least intense

$4=$ most intense

Social Desirability: $-2.000=$ Very Undesirable

$-1.000=$ Slightly Undesirable

$0.000=$ Neutral

1. $000=$ Slightly Desirable

2. $000=$ Very Desirable 


\section{APPENDIX B \\ THE MARLOWE CROWNE SOCIAL DESIRABILITY \\ SCALE}

Before voting I thoroughly investigate the qualifications of all the candidates $(T)$

I never hesitate to go out of my way to help someone in trouble (T)

It is sometimes hard for me to go on with my work if I am not encouraged (F)

I have never intensely disliked anyone (T)

On occasion I have had doubts about my ability to succeed in life (F)

I sometimes feel resentful when I don't get my way (F)

I am always careful about my manner of dress $(\mathrm{T})$

My table manners at home are as good as when I eat out in a restaurant (T)

If I could get into a movie without paying and be sure I was not seen, I would probably do it $(\mathrm{F})$

On a few occasions, I have given up doing something because I thought too little of my ability (F)

I like to gossip at times (F)

There have been times when I felt like rebelling against people in authority even though I knew they were right (F)

No matter who I'm talking to, I'm always a good listener (T)

I can remember "playing sick" to get out of something (F)

There have been occasions when I took advantage of someone (F)

I'm always willing to admit it when I make a mistake (T) 
I always try to practice what I preach $(\mathrm{T})$

I don't find it particularly difficult to get along with loud mouthed, obnoxious people $(\mathrm{T})$

I sometimes try to get even, rather than forgive and forget $(T)$

When I don't know something I don't at all mind admitting it $(\mathrm{T})$

I am always courteous, even to people who are disagreeable (T)

At times I have really insisted on having things my own way (F)

There have been occasions when I felt like smashing things (F)

I would never think of letting someone else be punished for my wrongdoing $(T)$

I never resent being asked to return a favor $(T)$

I have never been irked when people expressed ideas very different from my own $(\mathrm{T})$

I never make a long trip without checking the safety of my car (T)

There have been times when I was quite jealous of the good fortune of others (F)

I have almost never felt the urge to tell someone off (T)

I am sometimes irritated by people who ask favors of me (F)

I have never felt that I was punished without cause (T)

I sometimes think when people have a misfortune they only got what they deserved (F)

I have never deliberately said something that hurt someone's feelings (T)

Score one point for each response which agrees with the key. 